\section{IEEE TRANSACTIONS ON COMPUTER SOCIETY RESEARCH OUTPUT: A SCIENTOMETRIC STUDY.}

KEY WORDS: IEEE, Computer Society, Analysis, Transaction, Research Output

\section{Manase \\ Prabu. F*}

\section{Senthillkumar. $\mathbf{R}$}

Ph.D Scholar, Centre for Research and Evaluation, Bharathiar University, Coimbatore. *Corresponding Author

Librarian (S/G) \& Head-Research, DLIS, Kongunadu Arts and Science College (Autonomous), Coimbatore, Tamilnadu, India.

The paper presents the Scientometric Analysis of selected Thirty Transactions (Journals) of IEEE Computer Society for the period 2007-2016. The data for the study has been retrieved from the sources of Web of Science, Scopus, and IEEE Xplore. The study reveals that the publications productivity of the outcome of Computer Society Transactions on IEEE has obtained optimum level with 29258 publications from 30 number scholarly Transactions It has been recorded the highest publication as 4211 in the year 2016 with $14.3 \%$ followed by 3844 papers in 2015 with $13.1 \%$ and 3835 papers in 2014 with $13.1 \%$. The findings of source-wise distribution of Computer Society Transactions on IEEE research output bring out the facts that the journal articles' has constituted 27389 (94\%) of the total document's Source. The Maximum Transactions $(33 \%)$ were published on the subject ICT.

\section{INTRODUCTION}

Scientometrics and Bibliometrics are used to measure scientific activities, mainly by producing statistics on scientific publications indexed in databases. They are flexible tools used to study the sociological phenomena associated with scientific communities to conduct scientific/strategic, technical, technological, or competitive monitoring to design and manage research programs and to evaluate research. They are extremely valuable methods for evaluating research output, positioning studies, and conducting foresight studies in science and technology.

\section{Web of Science}

The Web of Science is the world's most trusted publisherindependent global citation database. Guided by the legacy of Dr. Eugene Garfield, inventor of the world's first citation index, the Web of Science is the most powerful research engine, delivering your library with best-in-class publication and citation data for confident discovery, access, and assessment.

\section{Scopus}

Scopus is Elsevier's abstract and citation database launched in 2004 . Scopus covers nearly 36,377 titles (22,794 active titles and 13,583 inactive titles) from approximately 11,678 publishers, of which 34,346 are peer-reviewed journals in top-level subject fields:life sciences, social sciences, physical sciences, and health sciences. It covers three types of sources: book series, journals, and trade journals. All journals covered in the Scopus database are reviewed for sufficiently high quality each year according to four types of numerical quality measure for each title; those are $h$-Index, CiteScore, SJR (SCImago Journal Rank), and SNIP (Source Normalized Impact per Paper). Searches in Scopus also incorporate searches of patent databases. ${ }^{[1]}$

\section{IEEE Xplore}

IEEE Xplore digital library is a research database for discovery and access to journal articles, conference proceedings, technical standards, and related materials on computer science, electrical engineering, and electronics, and allied fields. It contains material published mainly by the Institute of Electrical and Electronics Engineers (IEEE) and other partner publishers. IEEE Xplore provides web access to more than 5 million documents from publications in computer science, electrical engineering, electronics, and allied fields. Its documents and other materials comprise more than 300 peer-reviewed journals, more than 1,900 global conferences, more than 11,000 technical standards, almost 5,000 ebooks, and over 500 online courses. Approximately 20,000 new documents are added each month. Anyone can search IEEE $X$ plore and find bibliographic records and abstracts for its contents, while access to full-text documents may require an individual or institutional subscription

\section{IEEE Computer Society}

IEEE Computer Society (sometimes abbreviated the Computer Society or CS) is a professional society of the Institute of Electrical and Electronics Engineers (IEEE). Its purpose and scope are "to advance the theory, practice, and application of computer and information processing science and technology" and the "professional standing of its members". The CS is the largest of 39 technical societies organized under the IEEE Technical Activities Board.

\section{Review of Literature}

Shivappa Sangam L, Uma Arali. B, Patil, C.G \& Gani, S.R $(2014)^{65}$ has presented paper is an attempt to assess the research output of genetics research based on the distribution of publications in different sub-specialties of genetics. The study compares the research priorities of 16 sub-specialties of genetics in 10 Asian countries for two timespans; 1992-2001 and 2002-201 1, using the PubMed database. Since the raw publication counts are confounded by the size of the countries and the size of the subject specialties, the crossnational comparison is made using a relative indicatorResearch Priority Index.

Ganesh Surwase, Lalit Mohan, Kademani, B.S \& Bhanumurthy, $\mathbf{K}(\mathbf{2 0 1 4})^{66}$ have analyzed to aimed at analyzing the global publication trends on food preservation using the Scopus database for the period 1998-2012. The database contained 17511 publications on food preservation. The study analyzed the broad features of literature on food preservation focusing on the year-wise distribution of publications, highly productive countries, international collaboration, activity index, highly productive institutes, methods of food preservation, preservation by food types, and channels of communication.

\section{Statement of the Problem}

This title was selected for the study because "Computer Society Transactions on IEEE" is a leading publication in the field of Electrical, Electronic Engineering, Computer Science, and Technology. It is available all over the world both in printed as well as in the form of electronic journals.

\section{Objectives of the Study}

- To evaluate the growth performance of the selected journals published by Computer Society Transactions on IEEE during 2007-2016 
- Overall distribution pattern of contribution

- Year wise distribution pattern of contribution

- To identify the type of sources wise distribution

- To examine the subject dispersion of articles/periodicals

- To identify the Transactions indexed with various sources

\section{Scope of the Study}

The study covers a period of Ten Years from 2007-2016. Thirty Transactions have been selected for the present study from the world-leading membership organizations of IEEE Computer Society. The data have been collected from the sources ofWeb of Science, Scopus, and IEEE Xplore.

\section{Methodology}

The research output of the IEEE Computer Society required for the present study was extracted from the Web of Science, Scopus, and IEEE Xplore databases. The publications output from 2007-2016 has been considered for the study. Twenty Three Transactions are indexed with WoS, Six Transactions

are indexed with Scopus, and the remaining one is indexed with IEEE Xplore. To get appropriate data, the Computer Society Transactions on IEEE based on concern database in search with the tag 'IEEE Transactions on Very Large Scale Integrated System (VLSI)' etc was made which resulted in the availability of 29258 documents. The same data was filtered for a year, author name, subject area, document type, and affiliation-based search to get the results for the concerning parameters. The output of 29258 was exported to 'Microsoft Office Excel and SPSS softwares for getting appropriate results.

\section{IEEE Publications}

The IEEE Computer Society is a leading publisher of technical material in computing. Its publications include 12 peerreviewed technical magazines and 20 scholarly journals called Transactions, as well as conference proceedings, books, and a variety of digital products.

\section{DATA ANALYSIS AND INTERPRETATION}

\section{Table 1: Overall Distribution Pattern of Contribution}

\begin{tabular}{|c|c|c|c|c|c|c|c|c|c|c|c|c|c|}
\hline S.N & Name of the Transactions & 2007 & 2008 & 2009 & 2010 & 2011 & 2012 & 2013 & 2014 & 2015 & 2016 & Total & $\%$ \\
\hline 1 & IEEE Transactions on Computers & 149 & 139 & 137 & 142 & 145 & 150 & 205 & 251 & 284 & 309 & 1911 & 6.53 \\
\hline 2 & IEEE/ACM Computational Biology and Bioinformatics & 66 & 55 & 64 & 71 & 153 & 175 & 146 & 118 & 148 & 109 & 1105 & 3.77 \\
\hline 3 & $\begin{array}{l}\text { IEEE Transactions on Dependable and Secure } \\
\text { Computing }\end{array}$ & 26 & 20 & 28 & 34 & 70 & 73 & 30 & 48 & 54 & 57 & 440 & 1.50 \\
\hline 4 & IEEE Transactions on Haptics & 0 & 12 & 25 & 31 & 32 & 39 & 49 & 52 & 49 & 57 & 346 & 1.18 \\
\hline 5 & $\begin{array}{l}\text { IEEE Transactions on Knowledge and Data } \\
\text { Engineering }\end{array}$ & 123 & 131 & 128 & 133 & 136 & 164 & 216 & 226 & 249 & 244 & 1750 & 5.98 \\
\hline 6 & IEEE Transactions on Learning Technology & 0 & 25 & 35 & 38 & 34 & 34 & 36 & 36 & 34 & 39 & 311 & 1.06 \\
\hline 7 & IEEE Transactions on Mobile Computing & 106 & 109 & 120 & 129 & 130 & 163 & 193 & 214 & 186 & 225 & 1575 & 5.38 \\
\hline 8 & IEEE Transactions on Parallel and Distributed System & 136 & 128 & 138 & 138 & 191 & 223 & 226 & 307 & 283 & 275 & 2045 & 6.98 \\
\hline 9 & $\begin{array}{l}\text { IEEE Transactions on Pattern Analysis and Machine } \\
\text { Intelligence }\end{array}$ & 191 & 187 & 188 & 178 & 199 & 195 & 229 & 194 & 196 & 193 & 1950 & 6.66 \\
\hline 10 & IEEE Transactions on Services Computing & 0 & 25 & 35 & 34 & 31 & 47 & 46 & 54 & 73 & 78 & 423 & 1.44 \\
\hline 11 & IEEE Transactions on Software Engineering & 55 & 56 & 54 & 58 & 51 & 85 & 99 & 64 & 63 & 62 & 647 & 2.21 \\
\hline 12 & $\begin{array}{l}\text { IEEE Transactions on Visualization and Computer } \\
\text { Graphics }\end{array}$ & 181 & 168 & 167 & 160 & 238 & 272 & 271 & 252 & 130 & 245 & 2084 & 7.12 \\
\hline 13 & IEEE Annals of the History of Computing & 59 & 55 & 47 & 37 & 28 & 34 & 35 & 34 & 35 & 31 & 395 & 1.35 \\
\hline 14 & IEEE Transactions on Affective Computing & 0 & 0 & 0 & 13 & 20 & 44 & 38 & 37 & 35 & 34 & 221 & 0.75 \\
\hline 15 & IEEE/CAA Journal of Automatic Sinica & 0 & 0 & 0 & 0 & 0 & 0 & 0 & 53 & 53 & 53 & 159 & 0.54 \\
\hline 16 & IEEE Journal of Biomedical and Health Informatics & 0 & 0 & 0 & 0 & 0 & 0 & 121 & 213 & 214 & 169 & 717 & 2.45 \\
\hline 17 & IEEE Transactions on Control of Network Systems & 0 & 0 & 0 & 0 & 0 & 0 & 0 & 39 & 38 & 34 & 111 & 0.37 \\
\hline 18 & IEEE Transactions on Cloud Computing & 0 & 0 & 0 & 0 & 0 & 0 & 17 & 37 & 34 & 35 & 123 & 0.42 \\
\hline 19 & $\begin{array}{l}\text { IEEE Transactions on Computational Intelligence and } \\
\mathrm{Al} \text { in Games }\end{array}$ & 0 & 0 & 47 & 47 & 45 & 40 & 52 & 59 & 52 & 60 & 402 & 1.37 \\
\hline 20 & IEEE Transactions on Computational Social Systems & 0 & 0 & 0 & 0 & 0 & 0 & 0 & 15 & 16 & 17 & 48 & 0.16 \\
\hline 21 & IEEE Transactions on Consumer Electronics & 260 & 294 & 342 & 394 & 265 & 193 & 120 & 97 & 73 & 59 & 2097 & 7.16 \\
\hline 22 & IEEE Transactions on Industrial Informatics & 34 & 32 & 46 & 70 & 73 & 99 & 242 & 231 & 163 & 229 & 1219 & 4.16 \\
\hline 23 & IEEE Transactions on Information Forensics and & 70 & 70 & 83 & 85 & 122 & 160 & 178 & 182 & 205 & 216 & 1371 & 4.68 \\
\hline 24 & IEEE Internet of Things Journal & 0 & 0 & 0 & 0 & 0 & 0 & 0 & 54 & 62 & 129 & 245 & 0.83 \\
\hline 25 & IEEE Transactions on Multimedia & 147 & 148 & 130 & 73 & 119 & 145 & 182 & 190 & 191 & 207 & 1532 & 5.23 \\
\hline 26 & IEEE Transactions on Nano Bioscience & 48 & 33 & 42 & 35 & 35 & 49 & 48 & 51 & 114 & 105 & 560 & 1.91 \\
\hline 27 & $\begin{array}{l}\text { IEEE Transactions on Network Science and } \\
\text { Engineering }\end{array}$ & 0 & 0 & 0 & 0 & 0 & 0 & 0 & 0 & 13 & 23 & 36 & 0.12 \\
\hline 28 & IEEE/ACM Transactions on Networking & 125 & 115 & 151 & 150 & 142 & 149 & 147 & 149 & 149 & 281 & 1558 & 5.32 \\
\hline 29 & IEEE Transactions on Smart Grid & 0 & 0 & 0 & 40 & 88 & 231 & 250 & 306 & 313 & 292 & 1520 & 5.19 \\
\hline 30 & $\begin{array}{l}\text { IEEE Transactions on VLSI (Very Large Scale } \\
\text { Integration Systems) }\end{array}$ & 142 & 177 & 176 & 189 & 240 & 242 & 240 & 272 & 335 & 344 & 2357 & 8.05 \\
\hline \multicolumn{2}{|c|}{ Total } & 1918 & 1979 & 2183 & 2279 & 2587 & 3006 & 3416 & 3835 & 3844 & 4211 & 29258 & 100 \\
\hline
\end{tabular}

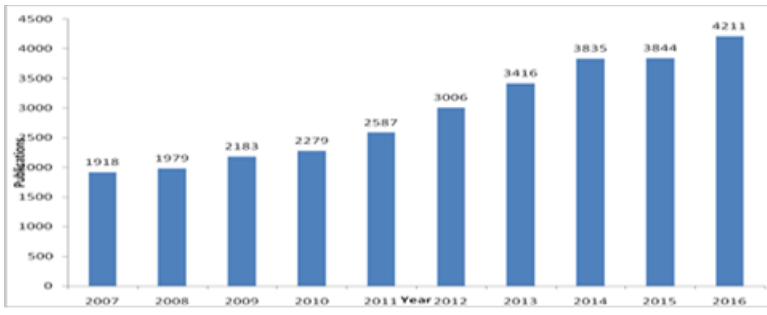

Figure 1: Overall Distribution Pattern of Contribution 
Table 1 \& Figure 1 show that there are Thirty Scholarly Transactions published by the IEEE Computer Society, which have been selected for the present study on the topic of "IEEE Transactions on Computer Society Research Output: A Scientometric Study". The list of selected Scholarly Transactions has been given in Table 1.The list of Transactions is selected based on its impact factors, the distribution pattern of contributions, the volume-wise distribution pattern of contribution, Year-wise distribution pattern of contributions, periodicity, citations, year of inceptions, subject areas of concentration for research, types of publications, and authorship patterns, etc.

The maximum number of papers have been published on "IEEE Transactions on Very Large Scale and Integrated System (VLSI)" 2357 (8.05\%), 29258. The minimum number of papers have been published on the "IEEE Transactions on Network Science and Engineering" 36, (0.12\%). The total number of papers published on "IEEE Computer Society" during the study period from 2007 to 2016 (Ten Years) was 29258. The distribution pattern of contributions has been significantly increased year by year. For instance, in the year 2007, only 1918 papers have been published and the same has been increased tremendously to 4211 in 2016.

Table 2:YearWise Distribution Pattern of Contribution

\begin{tabular}{|c|c|c|c|}
\hline S.No & Year & Publications & $\%$ \\
\hline 1 & 2007 & 1918 & $6.55 \%$ \\
\hline 2 & 2008 & 1979 & $6.76 \%$ \\
\hline 3 & 2009 & 2183 & $7.46 \%$ \\
\hline 4 & 2010 & 2279 & $7.78 \%$ \\
\hline 5 & 2011 & 2587 & $8.84 \%$ \\
\hline 6 & 2012 & 3006 & $10.2 \%$ \\
\hline 7 & 2013 & 3416 & $11.6 \%$ \\
\hline 8 & 2014 & 3835 & $13.1 \%$ \\
\hline 9 & 2015 & 3844 & $13.1 \%$ \\
\hline 10 & 2016 & 4211 & $14.3 \%$ \\
\hline \multicolumn{2}{|l|}{10 Years } & 29258 & $100 \%$ \\
\hline \begin{tabular}{|l|l|}
4500 \\
4000 \\
3500 \\
3000 \\
2500 \\
2000 \\
1500 \\
1000 \\
500 \\
0
\end{tabular} & 1918 & 4211 & \\
\hline & 2007 & 2016 & \\
\hline
\end{tabular}

Figure 2: YearWise Distribution Pattern of Contribution

Table 2 \& Figure 2 show the significant increase of publications published on the "IEEE Computer Society from 2007 to 2016 (Ten Years). It has published 1918 (6.55\%) papers published by the IEEE Computer Society in 2007.

In 2016, it has published 4211 (14.3\%) papers on IEEE Computer Society and it was also the most productive year of the contributions.

\section{YearWise Distribution Pattern of Contribution}

To find the relationship between the mean significant differences among the year-wise distribution pattern of contribution, a null hypothesis has been framed and discussed in the following table.

$\mathrm{H}_{0}$ : There is no mean significant difference between the yearwise distribution patterns of contribution during the study period.

Table 2.1 YearWise Distribution Pattern of Contribution

\begin{tabular}{|c|c|c|c|}
\hline S.No & Year & No. of Publications & AGR (\%) \\
\hline 1 & 2007 & 1918 & - \\
\hline 2 & 2008 & 1979 & 3.2 \\
\hline 3 & 2009 & 2183 & 10.3 \\
\hline
\end{tabular}

\begin{tabular}{|c|c|c|c|}
\hline 4 & 2010 & 2279 & 4.4 \\
\hline 5 & 2011 & 2587 & 13.5 \\
\hline 6 & 2012 & 3006 & 16.2 \\
\hline 7 & 2013 & 3416 & 13.6 \\
\hline 8 & 2014 & 3835 & 12.3 \\
\hline 9 & 2015 & 3844 & 0.2 \\
\hline 10 & 2016 & 4211 & 9.5 \\
\hline \multicolumn{2}{|c|}{ Mean } & $\mathbf{2 9 2 6}$ & \\
\hline \multicolumn{2}{|c|}{ SD } & $\mathbf{8 5 4 . 1}$ & \\
\hline \multicolumn{2}{|c|}{ CV (\%) } & $\mathbf{2 9 . 2}$ & \\
\hline \multicolumn{2}{|c|}{ CAGR (\%) } & $\mathbf{2 6 . 4 7}$ & \\
\hline \multicolumn{2}{|c|}{ 't' Value } & $\mathbf{3 . 0 1 6}$ \\
\hline \multicolumn{2}{|c|}{ Sig. } & $\mathbf{0 . 0 1 7 * *}$ & \\
\hline
\end{tabular}

Note : ** - Significant at $5 \%$ level

From the above table, it is noted that during the study period, the year -wise growth of the publications is continuously fluctuating. During the study period, 2012 has maximum growth of $16.2 \%$ and 2015 has registered its lowest growth as $0.2 \%$. On the whole, for the selected 10 years of the period, on an average 2926 publications are published with 29.2 percent consistency level. Also, 26.47 percent of the overall positive significant growth has recorded the number of publications. Finally, the significant result of the growth rate noticed that the null hypothesis is rejected.

\section{Table 3: Source Wise Distributions}

\begin{tabular}{|c|c|c|c|c|c|c|c|c|}
\hline Subjects & Articles & E M & PP & CN & Review & Letter & $\begin{array}{c}\text { Bio } \\
\text { Item }\end{array}$ & Total \\
\hline $\begin{array}{c}\text { Computer } \\
\text { Processing }\end{array}$ & 9825 & 365 & 321 & 77 & 133 & 17 & 14 & $\mathbf{1 0 7 5 2}$ \\
\hline $\begin{array}{c}\text { Networking } \\
\text { \& } \\
\text { Broadcasting }\end{array}$ & 5371 & 74 & 94 & 12 & 20 & 4 & 0 & $\mathbf{5 5 7 5}$ \\
\hline $\begin{array}{c}\text { Bio- } \\
\text { Engineering }\end{array}$ & 2114 & 82 & 150 & 14 & 20 & 2 & 0 & $\mathbf{2 3 8 2}$ \\
\hline $\begin{array}{c}\text { Signal } \\
\text { Processing }\end{array}$ & 2760 & 101 & 31 & 21 & 17 & 6 & 0 & $\mathbf{2 9 3 6}$ \\
\hline ICT \& Others & 7319 & 157 & 87 & 19 & 26 & 3 & 2 & $\mathbf{7 6 1 3}$ \\
\hline Total & $\mathbf{2 7 3 8 9}$ & $\mathbf{7 7 9}$ & $\mathbf{6 8 3}$ & $\mathbf{1 4 3}$ & $\mathbf{2 1 6}$ & $\mathbf{3 2}$ & $\mathbf{1 6}$ & $\mathbf{2 9 2 5 8}$ \\
\hline
\end{tabular}

- EM-Editorial Materials, PP : Proceeding Paper, CN : Correction, Bio-Item : Biographical Item

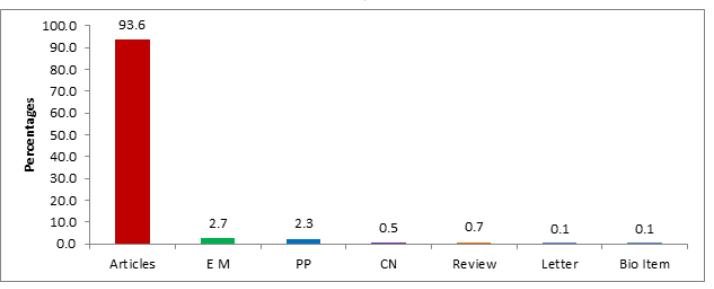

Figure 3: SourceWise Distributions

Table 3 \& Figure 3 show the papers which were contributed to the organizations of the IEEE Computer Society. Most of the papers were published in the form of articles 27389 (93.6 \%), followed by Editorial Materials 779 (2.7 \%), Proceeding Papers $683(2.3 \%)$, and published $143(0.5 \%)$ Corrections and $216(0.7 \%)$ Review Papers. Remaining forms like letter, biographical item etc is very less $32(0.1 \%), 16(0.1 \%)$ respectively. The types of publications are almost common in all the transactions published on the IEEE Computer Society.

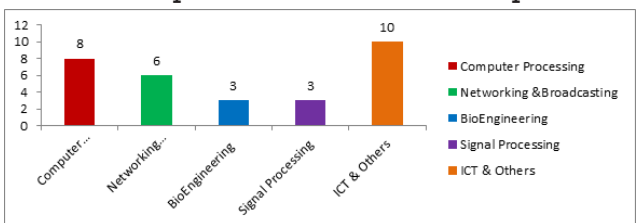

Figure 4: Subject Dispersion of Articles/ Periodicals Published by IEEE Computer Society 
It was observed from Figure 4 that the IEEE Transactions published on the subject "Computing Processing" 8 out of 30 which amounts to $27 \%$. Six Transactions published on the subject "Networking \& Broadcasting" amounts to $20 \%$. Three Transactions each published on the subject "Bio-Engineering \& Signal Processing, which amounts to $10 \%$ each. There were Ten Transactions published on the following subjects such as "ICT \& Others (Mathematical Application, Technology, Control System, Cloud Computing, Artificial Intelligence, Computational Social System, Waves \& Electromagnetic, Energy and Circuits)" amounts to $33 \%$. Therefore the maximum IEEE Transactions has been published their articles on the topic on "ICT \& Others"

Table 5 Transactions indexed with Sources Wise Published by IEEE CS

\begin{tabular}{|c|c|c|c|}
\hline S.No & Particulars & Transactions & $\%$ \\
\hline 1 & Web of Science & 23 & $77 \%$ \\
\hline 2 & Scopus & 6 & $20 \%$ \\
\hline 3 & IEEE Xplore & 1 & $3 \%$ \\
\hline \multicolumn{2}{|c|}{ Total } & $\mathbf{3 0}$ & $\mathbf{1 0 0} \%$ \\
\hline
\end{tabular}

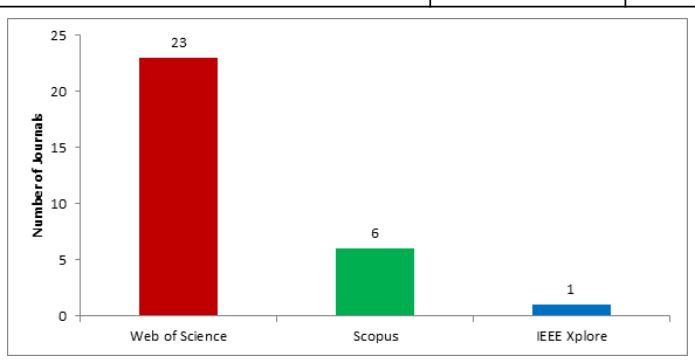

Figure 5: IEEE Transactions indexed with Sources

Table 5 \& Figure 5 show that the IEEE Computer Society Transactions were indexed with the sources of Web of Science, Scopus, and IEEE Xplore. There were 23 (77\%) Transactions of the IEEE Computer Society indexed with the Web of Science database, 6 (20\%) Transactions were indexed with the Scopus citation database and a Transaction which was indexed with IEEE Xplore 1 (3\%).

\section{Limitation of the Study}

- The data for the analysis have been retrieved from the sources of Web of Science, Scopus, and IEEE Digital Xplore only.

- The Study period covered only during 2007-2016.

- There is two statistical software, SPSS and MS Excel software alone is being used for data analysis.

- Thirty Transactions (Publications) of IEEE Computer Society only have been taken for the present study.

- The Computer Society (CS) Transactions on IEEE only have been studied out of 39 societies under the IEEE.

\section{Major Findings}

- IEEE Transactions on Computer Society has obtained optimum level with 29258 publications from 30 number scholarly Transactions

- The findings of research productivity in Computer Society Transactions on IEEE has the highest publication as 4211 in the year 2016 with $14.3 \%$

- The journal articles' has constituted 27389 (94\%) of the total document's Source,

- Among the top five subject categories, ICT \& others emerge as the topmost subject of research withlo (33\%) Transactions.

- The Maximum Transactions have been indexed with Web of Science Database $23(77 \%)$.

- Most of the articles, 10752 (37\%) have been published on the topic of "Computer Processing"

\section{CONCLUSION}

The study reveals that the research output of Computer
Society Transaction on IEEE, the literature growth is steadily increased year by year in terms of the overall distribution pattern of contribution, year-wise contribution, types of documents, source wise distribution, subject dispersion of periodicals, etc. The Maximum Transactions (33\%) were published on the subject ICT \& Others. Most of the publications were published in the form of articles 28143 (92.6\%). Understandably English is the popular medium of communication for research in IEEE Computer Society globally.

\section{REFERENCES}

1. http://wikipedia.org/scientoetrics, date from 1.03.2015 to 16.12 .2016

2. www.shodhganga.inflibnet.ac.in

3. http://publications.drdo.gov.in/index.php/djlit

4. Morales, M. (1985). Information and its Importance. International Forum for Information and Documentation. 10(2), 15-21.

5. Price.D.J. De sola (1963). Little Science/ Big Science: New York: Columbia University Press, 21.

6. Nalimov, V.V., \& Mulchenko Z.M (1969). Naukometriya. Izuchenie Razvitiya Nauki kakInformatsionnogo Protsessa. (Scientometrics Study of the Development of Science as an Information Process), Nauka, Moscow, (English translation:1971. Washington, D.C.: Foreign Technology Division. U.S. Air Force System Command, Wright-Patterson AFB, Ohio, (NTIS Report No.AD 735-634)

7. Beck,M.T.(1978).Editorial Statement. Scientometrics, 1,3-4

8. Tague-Sutcliffe, J.M (1992), An Introduction to informetrics, Information Processing \& Management 28: 1-3.

9. Bookstein, A. (1995). Implications of ambiguity for scientometric measurement. Journal of the American Society for Information Science and Technology, 52(1), 74-79.

10. De Solla Price,D.J.(1969). Citations of Literature, Acta cytologic, 13 (10), 544

11. Garfield,E.(1976). Significant journals of Science. Nature, 264,609-615.

12. http:// www.ieee.org, date from 1.03.2015 to 16.12 .2016

13. http://www.scopus.com (accessed 15 June 2015)

14. http://www.webofscience.com (accessed on 18 June 2015)

15. www.ieeexplore.ieee.org/Xplore/home.jsp

16 Simran Gupta \& Nabi Hasan (2018). Scientometric Analysis of Metamorphosis: A Journal of Management Research. DESIDOC Journal of Library and Information Technology, 38(4), 254-258.

17 Dhiman Mondal, Satish Kanamadi \& Kingsuk Das (2017). Contribution by Indian Authors in foreign origin Library and Information Science Journals during 2006-2015. A Scientometric Study, DESIDOC Journal of Library \& Information Technology, 37(6), 396. 